\title{
Comment on: Can postoperative atrial fibrillation after lung resections depend solely on the type of resection?
}

\author{
Tayfun Kermenli ${ }^{1}$, Cebrail Azar ${ }^{2}$ \\ ${ }^{1}$ Thoracic Surgery Clinic, Medicalpark Elazığ Hospital, Elazığ, Turkey \\ ${ }^{2}$ Chest Diseases Clinic, Medicalpark Elazığ Hospital, Elazığ, Turkey
}

Kardiochir Torakochir Pol 2019; 16 (4): 212

We read with great interest the article by Bagheri in the "Polish Journal of Thoracic and Cardiovascular Surgery" [1] which evaluated atrial fibrillation after lung surgery. We congratulate the author for a successful study that focused on an important issue.

However, postoperative atrial fibrillation (POAF) may occur due to several factors such as previous cardiac problems, advanced age, obesity, hypertension, poor cardiac function, chronic renal failure, chronic obstructive pulmonary disease, amount of peroperative bleeding and postoperative hypoxemia [2]. It was not specified whether the patients in the study had any cardiac problems before the operation, and it would be better to evaluate the patients statistically according to their age. We know that POAF is more common especially in elderly patients. On the other hand, postoperative amount of bleeding and hemogram values are also important, because hemogram decreasing due to hemorrhage can also cause POAF. In addition, perioperative blood transfusion is also associated with POAF, which was not mentioned in the study.

In conclusion, the cause of POAF is multifactorial and it is not enough to relate it to the type of lung resection, cardiopulmonary manipulation, and mediastinal lymphadenectomy that stimulates the pericardium and vagus nerve. We believe it would be more accurate to evaluate all the factors that could reveal POAF.

\section{References}

1. Bagheri R, Yousefi Y, Rezai R, Azemonfar V, Keshtan FG. Atrial fibrillation after lung surgery: incidence, underlying factors, and predictors. Kardiochir Torakochirur Pol 2019; 16: 53-56.

2. Lee SH, Ahn HJ, Yeon SM, Yang M, Kim JA, Jung DM, Park JH. Potentially modifiable risk factors for atrial fibrillation following lung resection surgery: a retrospective cohort study. Anaesthesia 2016; 71: 1424-1430.

Address for correspondence: Tayfun Kermenli MD, Thoracic Surgery Clinic, Medicalpark Elazığ Hospital, Olgunlar mh. Atatürk Bulvarı No. 5, 23700 Elazığ, Turkey, phone: +90 4242348000, e-mail: tayfunkermenli@gmail.com

Received: 24.10.2019, accepted: 24.11.2019. 